\title{
Instructors' Perspectives of Challenges and Barriers to Providing Effective Feedback
}

\author{
ABSTRACT \\ Instructor perspectives regarding the challenges they experience in enacting \\ effective feedback processes have not been the focus in the literature on effective \\ feedback processes. This study investigated the challenges that instructors \\ experienced in providing effective feedback to students between January and April \\ 2020, particularly considering campus closures and the shift to online learning in \\ response to the COVID-19 pandemic. This study consisted of six focus groups held \\ between January and April 2020 with five instructors from different disciplines at the \\ same institution with class sizes ranging from 14 to 82 . Through a thematic analysis \\ using a constant comparison method, it was found that the biggest challenges \\ instructors experienced in providing effective feedback was their own workload, the \\ disruption that student inaction on feedback brought to the feedback process, and \\ how the instructors managed their own affective responses and mindsets towards \\ feedback. These findings are discussed within the context of the COVID-19 \\ pandemic and based on these findings, recommendations for instructors include \\ considering their own limitations when designing feedback processes and checking \\ their beliefs about feedback with their students' perspectives on feedback in order \\ to align understanding.
}

KEYWORDS

classroom assessment, written feedback, feedback processes, instructor perspectives

\section{INTRODUCTION}

Research indicates that effective feedback has the power to improve student learning and performance, regardless of the context or discipline (Hattie and Timperley 2007; Shute 2008; Winstone and Carless 2019). However, even though feedback is considered to be a socially constructed process (Henderson et al. 2019b) in which instructors are responsible for establishing and maintaining the milieu of the classroom (Boud and Molloy 2013), student perspectives on what makes for effective feedback have taken precedence in the literature (Shields 2015; Winstone et al. 2017). Dawson et al. (2019) argued that instructors are more likely to make decisions about the feedback processes they use based on their own opinions, rather than based on published evidence. Therefore, research of effective feedback processes must also include the perspectives of academic staff, especially across a range of contexts (Dawson et al. 2019).

This study engaged instructors from across disciplines to explore the research question of "What challenges do instructors experience in providing effective feedback?" Given that most of the research on feedback in higher education is situated in Australia and the United Kingdom, this study provides a unique contribution to the literature by including a Canadian perspective. The findings inform both the theory of feedback processes as well as practical implications in the postsecondary 
teaching and learning context. Of note is that this research includes responses from both before and during the campus closure in response to the COVID-19 pandemic, which presented new and unique challenges for faculty in the feedback process.

\section{Effective feedback}

Effective feedback is described as feedback that learners use to make sense of their performance and improve the quality of their performance and their learning strategies (Henderson et al. 2019b). However, despite the amount of time and effort that instructors put into providing written feedback, many students make limited use of the feedback (Boud 2019; Winstone et al. 2017). This challenge has been attributed to instructor-centred models of feedback where learners are not required to take an active role in the feedback process (Carless and Boud 2018). Given these challenges with instructor-centred models, there has been a recent shift in the definition of feedback from a delivery model to a student-centred process of feedback (Dawson et al. 2019). At the centre of these student-centred models is the notion of student feedback literacy, defined as "the understandings, capacities and dispositions needed to make sense of information and use it to enhance work or learning strategies" (Carless and Boud 2018, 2). Essentially, a feedback literate student plays an active role in the feedback process and is essentially at the centre of the feedback process.

\section{Student perspectives on effective feedback}

While the student's role and perspective on feedback had been previously ignored in the feedback research (Carless et al. 2011; To 2021), several studies have investigated the reasons that postsecondary students do not take up feedback in meaningful ways (e.g., Agius and Wilkinson 2014; Burke 2009; Jonsson 2013; Winstone et al. 2017). The reasons for which students do not accept feedback reported in these studies can be grouped into the following categories: (1) unclear feedback, (2) untimely feedback, (3) lack of focus on improvement, and (4) lack of strategies for uptake.

Based on these challenges for students, there have been a few models proposed for providing useful and useable feedback based on students' perspectives of what makes feedback effective. These models provide guidance to instructors on how to give feedback (Gibbs and Simpson 2004), enhance student self-regulation (Nicol and Macfarlane-Dick 2006) or create environments conducive to the uptake of feedback (Leighton, Chu, and Seitz 2013). However, these guidelines also represent a siloed approach as they focus on feedback practices, learner factors, and institutional or contextual influences separately (Carless and Boud 2018; Henderson, Ryan, and Phillips 2019) and generally assume a provision model in which it is provided unidirectionally from the instructor.

\section{From student feedback literacy to teacher feedback literacy}

These models for providing effective feedback necessarily require the active participation of the instructor in providing high-quality feedback, yet student-centred models of feedback focus on the student role in the feedback process and de-emphasize the role of the instructor. The lived experiences of instructors as they engage in feedback has received little attention in the research literature (Dawson et al. 2019; Henderson, Ryan, and Phillips 2019; Tuck 2012). If we are to truly consider feedback as "inherently socially constructed and contextually situated" (Henderson et al. 2019a, 1238) it is necessary to consider the instructor's role and perspective. Moving in this direction, Carless and Winstone (2020) recently proposed the idea of teacher feedback literacy, defined as "the knowledge, expertise and dispositions to design feedback processes in ways which 
enable student uptake of feedback and seed the development of student feedback literacy" (4). This new concept is situated as necessarily intertwined with that of student feedback literacy.

Nevertheless, there is still little research focused on the perspectives of the instructors as they engage in designing and enacting feedback processes, despite their responsibility to create learning environments which are feedback rich and conducive to uptake (but see Carless 2006; Li and De Luca 2014; Orsmond and Merry 2011). Designs for feedback processes that support the likelihood that students will take up the provided feedback must also reduce the barriers and challenges experienced by the instructors in giving effective feedback, as well as not introduce new ones. But, before we can know which feedback models and processes reduce these barriers and challenges, we must become familiar with what they are.

\section{METHODS}

The purpose of this study was to explore the challenges and barriers that instructors experience in providing effective feedback in order to inform the design of effective feedback processes as part of a larger design-based research project, with the aim of developing a set of principles for instructors to follow when designing feedback processes. This design-based approach fits well with the purposes of this study given the focus on pedagogical design, solving complex problems, and partnership with instructors (Anderson and Shattuck 2012; McKenney and Reeves 2012; To 2021).

\section{Participants}

This research was conducted at a large research-intensive university in Western Canada. Instructors were recruited in November and December 2019 in preparation for the project to begin in January 2020. Research was approved through the university's ethical review process prior to the recruitment phase. The instructors were recruited through purposeful sampling, first through my own contacts and then those contacts recommending my study to others, with a view to obtain diversity in discipline and class size. Ultimately, five instructors from four disciplines took part in the study and each identified a single course and therefore a single formative feedback process that would be included in the study. All five courses selected were second-year, undergraduate courses but varied in class size, as described in table 1 .

\section{Table 1. Summary of participants}

\begin{tabular}{lccc} 
Instructor & Discipline & Class size & Feedback process \\
\hline A & Modern foreign languages & 26 & Audio feedback \\
B & Modern foreign languages & 14 & Scaffolded feedback \\
C & Sociology & 52 & Peer feedback \\
D & Humanities & 77 & Feedback on drafts \\
E & Medical sciences & 82 & Reflection on feedback \\
\hline
\end{tabular}

\section{The feedback processes}

As mentioned above, each instructor identified a single formative feedback process that would be included in the study, in terms of a point of focus for reflection within the instructor focus groups. Each of the feedback processes was described as follows:

1. Instructor A, audio feedback - The instructor asked students to keep a written learning log. Audio feedback in the form of a recording is then provided on the written learning log. 
2. Instructor B, scaffolded feedback - The research paper has multiple sections, each with a different deadline. Written feedback is provided on each section.

3. Instructor $\mathrm{C}$, peer feedback - The instructor created guidelines for peer feedback, based on the rubric, which students used to provide feedback on the research paper. The peer feedback was reviewed by the instructor and graded.

4. Instructor D, feedback on drafts - Instead of one longer research paper, the instructor split the writing task into a series of blog posts. Students were expected to write 200 words each week on the discussion board within the Learning Management System (LMS) with the instructor and peers providing feedback. Students were invited to edit each blog post before final submission.

5. Instructor E, reflection on feedback - After receiving feedback on each assignment, the instructor asked students to write a reflection on the feedback with provided prompts. Students were required to submit this reflection with the next assignment.

\section{Data collection and analysis}

Focus groups were undertaken in order to gain insights into the instructors' experiences in designing and implementing feedback processes in their identified courses, focusing on the barriers and challenges. All five instructors participated in six, hour-long focus group sessions, allowing for a longitudinal view of their experiences across the semester, between January and April 2020. Though I had a series of questions I brought with me to each focus group, the use of focus groups as opposed to a survey allowed us to explore, as a group of instructors, what was significant to the participants, rather than just what was significant to me (Tuck 2012).

Each focus group was scheduled for one hour, the first three of which took place in person and the last three took place over video conference due to campus closure in March 2020 because of the COVID-19 pandemic. I began each focus group with a specific question, but then allowed the conversation to flow as directed by the participants, sometimes asking follow-up or probing questions. The instructors commented on their experiences with implementing feedback in their courses, the transition to online teaching, and challenges and successes with feedback in general.

The first focus group focused on the instructors' beliefs about feedback including the purpose of feedback, how they recognized students' use of feedback, and their beliefs about students' perceptions of feedback. The second focus group began with a question on how the instructors made decisions about how and when to give feedback. The third focus group centred on how their feedback processes were progressing to date and what changes or tweaks were being made to each process. The fourth focus group took place one week after the campus closed due to the COVID-19 pandemic. It took place online and focused on how the transition to online teaching was going and whether this had impacted their feedback processes or how they saw students using feedback. The fifth focus group focused on evidence of students' use of feedback and reflecting on potential changes to the feedback process to enhance students' uptake of the feedback. The sixth focus group also centered on this reflection question of things the instructors might change in order to improve their selected feedback process. The focus of their reflections was on the courses listed in table 1 , however there were also occasional comparisons to other courses they were teaching that semester.

The focus groups were audio recorded and transcribed verbatim and analysed thematically. Initially, I coded the data inductively, looking for the emotions, values, and actions of the instructors in relation to their experiences of enacting these feedback processes, detecting patterns in the data (Saldaña 2016). Using the constant comparison method (Saldaña 2016), I continuously compared the emerging themes to arrive at larger categories. Though the instructors reflected on their own 
unique feedback processes that they used within their own courses, the analysis focused on finding common challenges and barriers. As a means of validating the findings, the themes were shared with the participants and refined based on their input. These interactions were conducted over email.

\section{FINDINGS}

The conversations that occurred in the focus groups revealed three general categories of challenges that the instructors experienced when trying to provide effective feedback: workload, student action (or inaction), and affect and mindset.

\section{Workload}

The instructors reported high workload as a challenge to providing feedback. This was the case for those with larger classes (here defined as over 50 students) as well as those with smaller classes who experienced practical or technical challenges. In regard to the larger classes, the high workload was not only because of the time it takes to provide thoughtful feedback for each student, but also because of high administrative loads such as responding to students' questions about their assignments by email. The administrative workload also increased after the campus closures as students were not able to ask their questions in class in the same way. Additionally, practical concerns also arose in March as the campus closed and courses were moved online in response to the COVID-19 pandemic which also led to increased workload due to technical challenges and constraints introduced by the LMS.

Large class sizes (larger than 50 students) proved a significant barrier to providing effective written feedback for members of the focus group. When one instructor attempted giving consistent, ongoing written feedback to the students as they engaged in a series of blog posts throughout the semester, she remarked, "I was dying...I had 80 , I was doing it in two classes, 80 students in one and then 40 students in another, which was a lot of grading." This resulted in some instructors reporting that they were spending less time providing feedback or necessarily reducing the amount of time they spent with each student's work in order to stay on top of their workload. For example, one instructor reported that they "actually started advising [their] TAs (teaching assistants) not to provide extensive feedback and if students have questions they can come to you because it's a waste of our time as it works right now."

In addition to the increase in workload from providing feedback in larger classes, large class sizes also influenced the instructors' workload in that the amount of administrative work per course was also more. While student questions might be better addressed in office hours, it became inevitable that they were dealing with a high number of emails, because "for the large classes where you have so many students and you can only see so many. Even if you do have office hours and they do come you can only see so many in a day." This became particularly problematic after the campus closed in March and courses moved online. As one instructor remarked, "I'm dealing with like 40, 50 student emails every day...So I can't even keep up with like all of the administrative work." This then in turn impacts the amount of time that can be devoted to providing effective feedback.

In addition to deciding when and how to provide feedback, several of the instructors in the focus group commented that they had faced significant technical and practical challenges that resulted in increased workload. For example, Instructor B who opted to provide audio feedback on the learning logs with a smaller class size (26 students) did not experience the same challenge in terms of amount of grading but encountered challenges in the move to working from home and finding time to record the feedback with minimal background noise or distractions. 
The technical issues included inconsistent home internet connections, sharing resources with children at home, the constraints of the LMS, and technology glitches. "[I] had to completely re-record one of my two-hour lectures because it hadn't recorded, so I lectured to an empty Zoom meeting room." In another example, one of the instructors also commented on how, due to the campus closure, they were unable to retrieve student work from campus to return to students, therefore also disrupting the feedback cycle. "Some of those tests had been trapped in my office until Monday when I was able to go pick them up."

They then also invested time in setting up their home office with the required infrastructure to provide students with the written feedback from a distance.

I also had to get help, you know, installing my home scanner on my work computer. So, I finally was able to send them feedback on their first test, the handful of students who missed the day I handed it back in class.

Instructors also found that the rules were constantly changing in terms of what was allowed or not for how to conduct assessments after courses were transitioned online suddenly in March. This led to an increased workload as instructors made shifts and changes to what they were doing.

Plus, all of the agitation of having like the rules constantly changing on you. And then, you know, you conceptualize one thing and then all of a sudden, two days later you learned that you could not do that or should not do that.

This resulted in instructors investing time to rethink and change assignments. For example, one instructor decided to abandon a component of the planned feedback cycle for the course, because they found the workload so difficult to keep up with. "... The feedback form and I scrapped it for, for the last assignment right now because I'm just, I can't keep up right now with the workload."

\section{Perception of student action (or inaction)}

Instructors' perceptions of student action, or lack thereof, presented a significant challenge to providing effective feedback as the topic came up regularly in the focus group discussions. These challenges involved students not submitting drafts for feedback, not accessing the feedback provided, not trusting the peer feedback, and technical issues that students themselves experienced which impacted their participation in the feedback process.

Despite the instructors designing feedback processes that included time to respond to feedback or peer feedback, the instructors described situations in which students did not submit work in time to receive feedback or did not pick up or look at the feedback provided. For example, one feedback model employed by instructors in this study was for students to write and submit drafts in order to receive either peer or instructor feedback in advance of the final submission. A significant challenge for the instructors using this model was that there were students who would not submit the drafts in time to receive this feedback, let alone to act upon it. This created significant challenges for some of the instructors' planned feedback processes as, "that creates problems for their peer review process and frustration and anxiety," as this also means that another student does not receive peer feedback. Another instructor made a point of following up with students who had not yet posted a draft of their work on the course's online discussion board, and while the students were grateful for the reminder, this did not alleviate the issue. "I ended up sending an email on Sunday to 
61 students who haven't even posted yet. So they had been grateful. 'I'm sorry. I forgot, I haven't done it yet." These late or missing submissions then remove the opportunity for feedback, breaking the feedback cycle.

Student inaction in accessing the provided feedback was also a source of frustration for the instructors. Some pointed out that many students do not even access the feedback, evidenced in the percentage of students reading the feedback in the online LMS.

I know that in many cases, in our classes, students are not actually even looking at the feedback because when they submit it to [the LMS], I know that a lot of them don't actually access their feedback... Strong students actually do read the feedback and I would say about $60 \%$ don't.

Another instructor commented that students did not see value in the feedback process, only in the grade. "I give my students the opportunity to submit an outline of their paper, but unless it's got a grade attached to it, hardly anybody takes it up." Another remarked, "at the end of the semester, [I] always have students where I have all three assignments still my folder because they never come to class. They never pick up their papers or anything." This presented significant barriers to the feedback process as some instructors reported then providing less feedback in response. "I actually started advising my TAs not to provide extensive feedback and if students have questions, they can come to you because it's a waste of our time as it works right now."

Students' challenges with judging the quality of their own or their peers' work also presented a challenge to providing effective feedback through self- or peer-assessment. These instructors reported that students then often turned to the instructor for input on the feedback. For example, "a number of students who have made an appointment during office hours after the first round of peer feedback and said, so my peer said, X, I just want to check with you that that's actually right." Another instructor also reported that their teaching assistants were also noticing that students struggled with judging peer work, describing their challenge as "[when you have] pictures where you have to find a flaw in the second picture that isn't in the first and they just don't see it. To them it looks identical, and they don't see what the problem is."

The instructors also reflected on the students' own technical issues as a source of challenge that resulted in a lack of participation in the planned feedback processes. "One thing that strikes me though, with a number of my students that have had difficulty with various types of feedback in the LMS is because they are not using devices that support word processors." Another instructor also captured this sentiment in their reflection on the challenges that students had with a peer feedback assignment.

Getting them to have a word document and then use the common assumption and to track changes, function, to give feedback. That was a nightmare that took us almost two hours, because none of them had ever worked with that and they're like second-, third-year university students.

\section{Affect and mindset}

Students' lack of action on feedback often resulted in an affective response from the instructors themselves. The instructors expressed feeling frustrated by the lack of student response to the feedback. "It's a horrible feeling though, to know that they're not using it like that." 
Interestingly, when asked what they believed students' perception of feedback to be, most of the instructors felt that students held a negative view of feedback. For example, one instructor shared, "I think they have a purely negative perception of the feedback that they're being punished. That they're being criticized for the work that they've done. That their work is being ripped apart." This instructor also described how they tried to mitigate the students' negative feelings toward feedback, including not using red pen, but with little success.

Even though I provide it in green and I preface it with this feedback is given from a place of real caring, you know, you matter to me... It's still, they see it and they're just like, she hates me.

The instructors shared that they felt obligated to provide feedback, either ethically or as part of their job.

So like for me, like my personally, my life, I feel like I lose a lot of my life into that black hole reading the feedback. But nonetheless, for me, it feels like it's necessary for meeting my obligation in my particular teaching situation.

However, some instructors responded to this frustration by reducing the amount of feedback they provided because of the frustration they felt.

I stopped providing comments because I think there's like two people that come out of a hundred that would pick up their papers and so the problem with these kinds of writing assignments that I have is that there's like zero learning from it beyond doing the exercise itself.

\section{DISCUSSION}

The findings of this study demonstrate that instructors experience significant challenges when working to provide effective feedback to students and the ways in which feedback is influenced by external factors; feedback does not exist in a vacuum, but in the messiness of relationships, resource constraints, and everything in between. The challenges that these instructors experienced in providing effective feedback to their students included high workload as a result of large classes and institutional constraints in addition to the online shift due to the COVID-19 pandemic, student action (or inaction), and their own affect and mindset.

\section{Workload}

While some of the workload issues for these instructors may have been exacerbated by campus closure and the need to move courses online, large class sizes also proved a significant barrier to providing effective feedback for the members of this focus group. Providing effective feedback can take a significant investment of time (Boud 2019; Lee 2011) which is then compounded for these larger classes. These findings regarding instructor workload also echo those of Henderson, Ryan, and Phillips (2019) who found that time as a limited resource and the limitations of providing personalised feedback in large classes were significant challenges for academic staff. Boud and Molloy (2013) also found that high workload is a deterrent to effective feedback, yet class sizes continue to increase, and teaching staff continue to be overloaded, compounding the problem. Boud and Molloy also argued that sustainable feedback is feedback that students would continue to apply 
beyond the bounds of the single assignment, however, efforts towards this kind of feedback are also restricted by resource constraints such as time.

However, giving feedback is not something that can just be abandoned by the instructors as they felt it was an important part of their job. These findings are also consistent with those of Tuck (2012) who found that instructor feedback practices are often tied to institutional expectations. Feedback-giving is necessarily situated in disciplinary and institutional contexts that influence instructor action (Tuck 2012).

\section{Student action (or inaction)}

While workload and time to provide feedback influenced when and how feedback was provided, student inaction also had a major impact on the feedback cycle, at times completely breaking the cycle. The instructors described a lack of student action around submitting drafts in time for them to provide feedback as well as not trusting the peer feedback process. The reasons for the lack of action by the students align with Carless and Boud's (2018) framework for student feedback literacy. Carless and Boud stated that if students do not understand and appreciate the role of feedback in their learning, if they lack the ability to make judgements about their own work against a standard, and if they lack strategies for acting on feedback, they will not be able to participate in the feedback cycle. This was evident in the way that the instructors reported students not picking up feedback on assignments, not reviewing the feedback on the LMS, or not submitting drafts in time to receive peer feedback. This lack of action on the part of the students also had an impact on the instructors, as it led to an affective response that then had to be managed.

\section{Affect and mindset}

As discussed above, the students' lack of action on feedback resulted in an affective response from the instructors, who felt frustrated due to the lack of student engagement with the feedback, despite the time and effort that the instructor had invested. Additionally, instructors' belief that students viewed feedback as punishment was also seen to influence their ability to provide effective feedback. Carless (2006) also found that instructors had more negative beliefs about how students perceived feedback as compared to how students reported viewing feedback.

While there is little previous research on the perspectives of instructors as providers of feedback outside of Australia and the United Kingdom, the findings of the present study support Carless and Winstone's (2020) framework for teacher feedback literacy. In their framework, Carless and Winstone described teacher feedback literacy as involving "the design and management of assessment environments that enable students to develop feedback literacy capabilities” (2). Teacher feedback literacy consists of designing for uptake, relational sensitivities, and managing practicalities in order to support student feedback literacy and the uptake of feedback. This model recognizes that the instructor must not only provide high quality feedback, but also manage the practicalities of the teaching environment. The cyclical nature of Carless and Winstone's proposed model is also apparent when the feedback cycle breaks down. As exemplified in the findings of this study, if the instructor provides feedback but the students do not take up the feedback in a way that is expected or acceptable to the instructor, then the instructor may feel frustrated and provide less feedback in the future. Tuck (2012) also reported that instructors engaged more superficially with student work or provided more superficial feedback as a time saving measure.

Henderson, Ryan, and Phillips (2019) also found that staff were concerned with a lack of student engagement with feedback, reporting that instructors felt that the lack of student engagement with feedback was a challenge to the feedback process. They concluded that feedback is 
influenced not only by the outlooks of the learners receiving feedback, but also by the outlook of the instructors, reinforcing the importance of taking instructors' experiences into consideration when designing feedback processes.

\section{Impact of the pandemic}

These findings must also be viewed in light of the significant disruption that COVID-19 and the move to online teaching and learning caused to the feedback processes of these instructors. It is clear that the pandemic exacerbated challenges for instructors (Reynolds et al. 2020) and contributed to an overall negative perception of the effects of teaching online (Barton 2020). As described above, there was an increase in administrative workload which took time away from feedback processes as well as technical disruptions which delayed the timely provision of feedback. While some faculty have previous online teaching experience to draw upon, others have little such experience (Day et al. 2021). Reynolds et al. (2020) also found that instructors had to overcome barriers to including writing assignments as part of their online teaching, some of which are in line with the findings from this study such as a high workload and constraints due to large class sizes. It is significant that some of the challenges experienced by the instructors in this study would not have arisen if classes continued in person, however these challenges should not be ignored as we move forward with the potential for moving back to primarily in person classes.

\section{CONCLUSION}

While this study was purposefully limited by the number of participants, there were also limitations that arose due to the transition to online teaching and learning in March 2020, resulting in the instructor focus groups also moving online. This included a move to online focus groups rather than in person and unusual shifts in the feedback processes of these instructors, as described above. While it will be useful to repeat this study once classes have fully returned in person, there are important considerations for instructors and administrators that have been surfaced through this deeper exploration of the challenges and barriers that instructors must overcome to enable effective feedback practices in their courses.

\section{Implications for the classroom and design of feedback processes}

The findings of this study can readily be applied by instructors to the classroom environment, both in the remote-adapted classroom as well as when classes return face to face. Specifically, those designing feedback processes with the intention of increasing the likelihood that students will take up the provided feedback must also pay attention to the barriers and challenges instructors experience. If the feedback processes do not address these challenges, they will not be effectively used by the instructor. In the final focus groups, the instructors reflected on changes they would make to their feedback processes in order to better enable the uptake of feedback by their students. This included better managing their own workload through providing less, more focused feedback as well as adhering to strict deadlines for drafts (Paris 2021).

Henderson, Ryan, and Phillips (2019) asserted that the perceptions and outlook of the instructors can influence the effectiveness of feedback processes, instructors' experiences must be taken into consideration when designing those feedback processes. While it is often the instructor designing feedback processes, able to take their own preferences and perspectives into account, this is not always the case when there are courses with multiple sections taught by different instructors. Additionally, instructors should confront their affective response and mindset towards feedback by 
seeking out the students' perspectives of feedback in order to verify the beliefs that they hold. As Carless (2006) noted, because feedback is a social process, it may be interpreted in different ways.

\section{Future research}

This study contributes to the research on the perspectives of instructors as they engage in feedback processes, particularly in the Canadian context, as it describes the barriers and challenges that the instructors themselves experienced throughout the academic term. From this study it is clear that for any feedback process to be successful, the instructor's role in the process must be considered. While it is usually the instructor designing their own feedback processes, they may not be aware of how the design will reduce or add to their already existing challenges. Some of these challenges also go beyond the individual instructor, such as that of higher workload due to larger classes or constraints from the LMS that they are required to use, therefore any designs for feedback processes must take the instructor's experience in context into consideration. Any feedback process that increases instructor workload, or does not actively reduce instructor workload, are likely to be less successful than those designed with these considerations in mind.

Additionally, instructors must work to address their own mindsets about students' perceptions of feedback. Approaching feedback from a negative perspective, or assuming students view feedback negatively, may create new challenges for instructors. Future research investigating how instructors develop and change their mindsets would be useful in this arena. Despite the challenges that these instructors experienced in their efforts to provide effective feedback, they continued to offer feedback from a place of caring and a lens of compassion. A further investigation of the role of compassion in the provision of feedback would add a richer understanding of instructors' perspectives and experiences to the literature.

Given that this research took place amid the campus closures in response to the COVID-19 pandemic, it would also be beneficial to repeat the study when all classes have either returned to campus or been purposefully designed to be conducted in an online or remote format. This would allow a deeper understanding of how the COVID-19 disruption exacerbated the challenges the instructors' experienced beyond that of a typical semester.

\section{ACKNOWLEDGMENTS}

I thank my doctoral supervisor, Dr. Kim Koh, for her ongoing guidance and comments on earlier versions of this article. I am also grateful for the funding provided by the Social Sciences and Humanities Research Council of Canada Joseph-Armand Bombardier Canada Graduate Scholarships-Doctoral and the Killam Trust.

Brit M. Paris (PhD, 2021, University of Calgary, CA) is an Educational Developer at Capilano University in North Vancouver, Canada and a sessional instructor in the Werklund School of Education at the University of Calgary in Calgary, Canada. This study was conducted as part of her doctoral research, which focused on formative assessment practices in higher education.

\section{REFERENCES}

Agius, Natalie M., and Ann Wilkinson. 2014. "Students' and Teachers' Views of Written Feedback at Undergraduate Level: A Literature Review." Nurse Education Today 34 (4): 552-559. https://doi.org/10.1016/j.nedt.2013.07.005.

Anderson, Terry, and Julie Shattuck. 2012. “Design-Based Research: A Decade of Progress in Educational Research?" Educational Researcher 41 (1): 16-25. https://doi.org/10.3102/0013189X11428813.

Barton, Daniel C. 2020. "Impacts of the COVID-19 Pandemic on Field Instruction and Remote Teaching Alternatives: Results from a Survey of Instructors." Ecology and Evolution 10 (22): 12499-507. https://doi.org/10.1002/ece3.6628. 
Boud, David. 2019. "Foreword." In Designing Effective Feedback Processes in Higher Education, edited by Naomi E. Winstone and David Carless, xii-xiii. Abingdon: Routledge.

Boud, David, and Elizabeth Molloy. 2013. "Rethinking Models of Feedback for Learning: The Challenge of Design." Assessment and Evaluation in Higher Education 38 (6): 698-712. https://doi.org/10.1080/02602938.2012.691462.

Burke, Dierdre. 2009. "Strategies for Using Feedback Students Bring to Higher Education." Assessment and Evaluation in Higher Education 34 (1): 41-50. https://doi.org/10.1080/02602930801895711.

Carless, David. 2006. "Differing Perceptions in the Feedback Process." Studies in Higher Education 31 (2): 219 233.

Carless, David, and David Boud. 2018. "The Development of Student Feedback Literacy: Enabling Uptake of Feedback." Assessment and Evaluation in Higher Education 2938 (May): 1-11. https://doi.org/10.1080/02602938.2018.1463354.

Carless, David, Diane Salter, Min Yang, and Joy Lam. 2011. "Developing Sustainable Feedback Practices." Studies in Higher Education 36 (4): 395-407. https://doi.org/10.1080/03075071003642449.

Carless, David, and Naomi Winstone. 2020. "Teacher Feedback Literacy and Its Interplay with Student Feedback Literacy Feedback Literacy." Teaching in Higher Education, 1-14. https://doi.org/10.1080/13562517.2020.1782372.

Dawson, Phillip, Michael Henderson, Paige Mahoney, Michael Phillips, Tracii Ryan, David Boud, and Elizabeth Molloy. 2019. "What Makes for Effective Feedback: Staff and Student Perspectives." Assessment and Evaluation in Higher Education 44 (1): 25-36. https://doi.org/10.1080/02602938.2018.1467877.

Day, Terence, I-Chun Catherine Chang, Calvin King Lam Chung, William E. Doolittle, Jacqueline Housel, and Paul N. McDaniel. 2021. "The Immediate Impact of COVID-19 on Postsecondary Teaching and Learning." Professional Geographer 73 (1): 1-13. https://doi.org/10.1080/00330124.2020.1823864.

Gibbs, Graham, and Claire Simpson. 2004. "Conditions Under Which Assessment Supports Students' Learning." Learning and Teaching in Higher Education 2004-05 (1): 3-31.

Hattie, John, and Helen Timperley. 2007. "The Power of Feedback." Review of Educational Research 77 (1): $81-$ 112. https://doi.org/10.3102/003465430298487.

Henderson, Michael, Tracii Ryan, and Michael Phillips. 2019. “The Challenges of Feedback in Higher Education." Assessment and Evaluation in Higher Education 44 (8): 1237-52. https://doi.org/10.1080/02602938.2019.1599815.

Henderson, Michael, Tracii Ryan, David Boud, Phillip Dawson, Michael Phillips, Elizabeth Molloy, and Paige Mahoney. 2019a. "The Usefulness of Feedback." Active Learning in Higher Education, September, 146978741987239. https://doi.org/10.1177/1469787419872393.

Henderson, Michael, Michael Phillips, Tracii Ryan, David Boud, Elizabeth Molloy, and Paige Mahoney. $2019 \mathrm{~b}$. "Conditions That Enable Effective Feedback." Higher Education Research and Development 38 (7): 1-16. https://doi.org/10.1080/07294360.2019.1657807.

Jonsson, Anders. 2013. "Facilitating Productive Use of Feedback in Higher Education." Active Learning in Higher Education 14 (1): 63-76. https://doi.org/10.1177/1469787412467125.

Lee, Icy. 2011. "Working Smarter, Not Working Harder: Revisiting Teacher Feedback in the L2 Writing Classroom." Canadian Modern Language Review/La Revue Canadienne Des Langues Vivantes 67 (3): 37799. https://doi.org/10.3138/cmlr.67.3.377.

Leighton, Jacqueline P., Man-Wai Chu, and Paolina Seitz. 2013. "Errors in Student Learning and Assessment: The Learning Errors and Formative Feedback (LEAFF) Model." In Informing the Practice of Teaching Using Formative and Interim Assessment: A Systems Approach., 185-208. https://www.lib.byu.edu/cgibin/remoteauth.pl?url=http://search.ebscohost.com/login.aspx?direct=trueanddb=psyhandAN=201310890-009andsite=ehost-liveandscope=site\%0Ahttp://jacqueline.leighton@ualberta.ca.

Li, Jinrui, and Rosemary De Luca. 2014. “Review of Assessment Feedback. Studies in Higher Education 39 (2): 378-393. https://doi.org/10.1080/03075079.2012.709494.

McKenney, Susan E., and Thomas C. Reeves. 2012. Conducting Educational Design Research. New York, NY: Routledge.

Nicol, David J., and Debra Macfarlane-Dick. 2006. "Formative Assessment and Self-regulated Learning: A Model and Seven Principles of Good Feedback Practice." Studies in Higher Education 31 (2): 199-218. https://doi.org/10.1080/03075070600572090.

Orsmond, Paul, and Stephen Merry. 2011. Feedback Alignment: Effective and Ineffective Links Between Tutors' and Students' Understanding of Coursework Feedback. Assessment \& Evaluation in Higher Education 36 (2): 125-136.

Paris, Brit M. 2021. “Designing Effective Feedback in Higher Education: 
Student and Instructor Perspectives." [Manuscript in preparation.] Werklund School of Education, University of Calgary.

Reynolds, Julie A., Victor Cai, Julia Choi, Sarah Faller, Meghan Hu, Arthi Kozhumam, Jonathan Schwartzman, and Ananya Vohra. 2020. "Teaching During a Pandemic: Using High-Impact Writing Assignments to Balance Rigor, Engagement, Flexibility, and Workload." Ecology and Evolution 10 (22): 12573-80. https://doi.org/10.1002/ece3.6776.

Saldaña, Johnny. 2016. The Coding Manual for Qualitative Researchers. 3rd ed. SAGE Publications Ltd. https://doi.org/10.19173/irrodl.v14i5.1626.

Shields, Sam. 2015. "'My Work is Bleeding': Exploring Students' Emotional Responses to First-year Assignment Feedback." Teaching in Higher Education 20 (6): 614-624. https://doi.org/10.1080/13562517.2015.1052786.

Shute, Valerie J. 2008. "Focus on Formative Feedback." Review of Educational Research 78 (1): 153-89. https://doi.org/10.3102/0034654307313795.

To, Jessica. 2021. “Using Learner-Centred Feedback Design to Promote Students' Engagement with Feedback." Higher Education Research and Development, February, 1-16. https://doi.org/10.1080/07294360.2021.1882403.

Tuck, Jackie. 2012. "Feedback-Giving as Social Practice: Teachers' Perspectives on Feedback as Institutional Requirement, Work and Dialogue." Teaching in Higher Education 217 (2): 209-21.

Winstone, Naomi E., and David Carless. 2019. Designing Effective Feedback Processes in Higher Education. Abingdon: Routledge.

Winstone, Naomi E., Robert A. Nash, James Rowntree, and Michael Parker. 2017. "'It'd Be Useful, but I Wouldn't Use It': Barriers to University Students' Feedback Seeking and Recipience." Studies in Higher Education 42 (11): 2026-41. https://doi.org/10.1080/03075079.2015.1130032. and copyright for the publication layout resides with the journal. These copyright holders have agreed that this article should be available on open access under a Creative Commons Attribution License 4.0 International (https://creativecommons.org/licenses/by-nc/4.0/). The only constraint on reproduction and distribution, and the only role for copyright in this domain, should be to give authors control over the integrity of their work and the right to be properly acknowledged and cited, and to cite Teaching \& Learning Inquiry as the original place of publication. Readers are free to share these materials-as long as appropriate credit is given, a link to the license is provided, and any changes are indicated. 